\title{
Percepção Motivacional dos Servidores de uma Instituição Pública Federal
}

\author{
Adalberto Campinho da Silva ${ }^{1}$; Bruno Cezar Silva² Maria Gabriela Jandiroba Silva ${ }^{3}$
}

\begin{abstract}
Resumo: Uma forma eficiente de diagnosticar o nível de motivação em um ambiente organizacional é por meio da expressão da percepção dos seus colaboradores. Nesse estudo propôs-se verificar o nível de motivação para o trabalho dos servidores de uma instituição pública federal, em Petrolina/PE, perante uma escala de motivação conhecida. Adotou-se a escala Multi-Moti, pois permite a identificação de quatro dimensões de motivação associadas ao trabalho. Aplicou-se um questionário fechado, constituído de itens demográficos e da escala motivacional relacionada a uma escala Likert de cinco pontos. Os resultados mostraram que o nível de motivação percebido pelos servidores é positivo, tendo obtido média geral de 3,31 pontos de 5,00. Que a expressão da percepção de motivação dos servidores face a motivação para realização e poder destacou-se como detentora da maior média, diferenciando-se significativamente das demais. Diferenciação correlacionada à percepção de fatores ligados diretamente ao enaltecimento, valorização e a perspectivas de ascensão profissional.
\end{abstract}

Palavras-chave: Motivação. Trabalho. Percepção. Multi-Moti.

\section{Motivational Perception of Servants of a Federal Public Institution}

\begin{abstract}
An efficient way of diagnosing the level of motivation in an organizational environment is through the expression of the perception of its collaborators. In this study it was proposed to verify the level of motivation for the work of the employees of a federal public institution, in Petrolina / PE, before a known motivation scale. The Multi-Moti scale was adopted, since it allows the identification of four dimensions of motivation associated with work. A closed questionnaire, consisting of demographic items and the motivational scale related to a five-point Likert scale, was applied. The results showed that the level of motivation perceived by the servers is positive, with a general average of 3.31 points of 5.00. That the expression of the motivation perception of the servers in the face of the motivation for achievement and power was highlighted as having the highest average, differing significantly from the others. Differentiation correlated to the perception of factors directly linked to the exaltation, valorization and the perspectives of professional ascension.
\end{abstract}

Key-words: Motivation. Work. Perception. Scale Multi-Moti.

\footnotetext{
${ }^{1}$ Pós-Graduando em Gestão Pública pela Universidade Federal do Vale do São Francisco. E-mail: acampsilva@ hotmail.com.

${ }^{2}$ Orientador, Mestre em Gestão de Políticas Públicas e Segurança Social pela Universidade Federal do Recôncavo da Bahia.

E-mail: bruno.cezar@univasf.edu.br.

${ }^{3}$ Coorientadora, Mestre em Administração pela Universidade Federal da Bahia - UFBA.

E-mail: gabriela.jandiroba@ univasf.edu.br.
}

206 Id on Line Rev. Mult. Psic. V.12, N. 41, p.206-218, 2018 - ISSN 1981-1179 


\section{Introdução}

A investigação daquilo que motiva as pessoas é algo bastante discutido e conceituado, havendo na literatura uma diversidade de teorias, muitas delas complementares sobre esse elemento básico do comportamento organizacional. Para Robbins (2010, p. 196) a motivação é consequência da interação do indivíduo com a situação, é um recurso responsável pela intensidade, direção e persistência dos esforços de uma pessoa para a obtenção de algo. E o nível de motivação é variável tanto entre duas ou mais pessoas, como também, em apenas uma só, a depender da circunstância.

No campo laboral, Brunelli (2008, p. 13/14) afirmou a motivação humana para o trabalho permanecer ainda como um dos grandes obstáculos das instituições, pois mesmo existindo inúmeras e complexas teorias, na prática, a motivação continua sendo vista com simplicidade, havendo poucas organizações que se preocupam com o comportamento de seus trabalhadores no ambiente de trabalho.

Chiavenato (1994, p. 179) declarou que a motivação é uma função gerencial, segundo ele, apesar de habitar o interior dos indivíduos ela pode ser significativamente influenciada por fatores externos ou pelo próprio trabalho em si. Em contrapartida, Lopes (2003) afirmou também, que a motivação tem relação direta com as necessidades das pessoas, relacionando o atendimento de uma necessidade à exteriorização de uma outra de nível mais alto.

Não raro os gestores se deparam com manifestações de insatisfação e desmotivação dos seus colaboradores, para Gomes e Quelhas (2013) esses sinais expressados através de reclamações e do comportamento imotivado percebidos no contato com os servidores podem ser indicativos da tendência danosa do modo pelo qual a gestão organizacional está sendo conduzida. Contudo, Robbins (2010, p. 159) alega que o comportamento das pessoas não está baseado na realidade objetiva e sim na percepção da realidade que elas têm.

$\mathrm{Na}$ ótica das afirmações preliminarmente sobrescritas, dada a importância substancial do gerenciamento do comportamento das pessoas numa organização, deduz-se ser, a investigação da percepção, uma interessante forma de diagnóstico do nível motivacional para o trabalho. Neste sentido, convém inferir, também, que a motivação estando ela atrelada a uma diversidade de fatores, poderia então, ser melhor examinada por meio da investigação da percepção externada pelos próprios trabalhadores acerca desses aspectos motivacionais. 
Segundo Ferreira et al. (2006), as empresas estão cada vez mais precisando identificar colaboradores bem motivados, alegando de que esses dão respostas mais eficazes face aos indicadores de desempenho e consequentemente rentabilizam a produtividade organizacional.

Nesse contexto, a captação das percepções motivacionais das pessoas de uma organização se respalda como de relevante importância, subsidiando a análise e compreensão das relações humanas existentes, contribuindo para identificação elementos estratégicos para o planejamento organizacional, auxiliando gestores em iniciativas para o trato e convivência com seus colaboradores, assim como, na indução de comportamento positivo, com vistas à melhoria do desempenho nas atividades laborais visto à estimulação motivacional ensejada.

E, foi então, a partir dessas concepções e buscando saber como se manifestavam as percepções de motivação dos servidores de uma unidade regional de uma instituição pública, que este estudo teve como objetivo verificar o nível de motivação para o trabalho, dos seus servidores, perante uma escala de motivação conhecida, a Escala Multi-Moti de Ferreira et al. (2006), para tanto, foi estabelecida, também, a determinação dos níveis motivacionais por categorias demográficas e dimensões motivacionais.

A escolha da Escala Multi-Moti foi motivada pelo fato de se tratar de uma escala multidimensional constituída de 28 itens que avaliam quatro diferentes dimensões de motivação para o trabalho vinculadas às respectivas teorias de motivação: Motivação com a organização do trabalho segundo a perspectiva teórica de Hackman e Oldham (1980); Motivação de realização e poder segundo a teoria das necessidades aprendidas de David McClelland (1975, 1987, 1979); Motivação para o desempenho, teoria Goal Setting de Locke \& Latham, (1990), e; Motivação para o envolvimento organizacional de Allen e Meyer (1990).

\section{Metodologia}

Trata-se de um estudo de natureza aplicada/exploratória com a adoção do procedimento de estudo de caso (YIN, 2010) que visou verificar e comparar, por meio da percepção dos servidores, o grau de motivação dos servidores da Superintendência Regional do Instituto Nacional de Colonização e Reforma Agrária no Médio São Francisco - INCRA SR29/MSF, sediada no município de Petrolina-PE. 
Para fins de levantamento de dados foi usado como instrumento de pesquisa o questionário fechado, constituído de duas seções, a primeira contendo cinco questões de cunho sociodemográfico e a segunda de vinte e oito afirmativas motivacionais advindas da Escala Multi-Fatorial de Motivação no Trabalho (Multi-Moti) de Ferreira et al. (2006).

Essas vinte oito afirmativas motivacionais trataram-se, na integra, dos fatores validados na escala Multi-Moti, conferindo uma escala tetrafatorial de motivação no trabalho aos moldes do apresentado no quadro 1.

Quadro 1: Escala tetrafatorial Muti-Moti.

\begin{tabular}{|c|c|}
\hline Dimensão & Fator \\
\hline $\begin{array}{l}\text { Organização no } \\
\text { trabalho }\end{array}$ & $\begin{array}{l}\text { 1. Esta organização tem condições de trabalho satisfatórias. } \\
\text { 5. Sinto-me realizado com as funções que desempenho na organização. } \\
\text { 9. Sinto-me satisfeito com a minha remuneração. } \\
\text { 13. O “feedback" que recebo no trabalho contribui enquanto fator motivacional. } \\
\text { 17. Todos os funcionários da organização participam nos processos de tomada de } \\
\text { decisão. } \\
\text { 21. Considero que trabalho num ambiente de cooperação entre colegas. } \\
\text { 25. A organização permite o desenvolvimento dos objetivos profissionais. }\end{array}$ \\
\hline Desempenho & $\begin{array}{l}\text { 2. Considero que as avaliações periódicas me motivam. } \\
\text { 6. Gostaria de ser avaliado(a) no meu desempenho periodicamente. } \\
\text { 10. No desempenho de tarefas é importante demonstrar alguma emotividade. } \\
\text { 14. Gosto de ser avaliado(a) no desempenho das tarefas. } \\
\text { 18. Habitualmente desenvolvo estratégias para alcançar as minhas metas. } \\
\text { 22. Tarefas diversificadas são importantes para o bom desempenho das funções. } \\
\text { 26. Existe competitividade no meu grupo de trabalho. }\end{array}$ \\
\hline Realização/Poder & $\begin{array}{l}\text { 3. Ter perspectivas de carreira é importante para a minha motivação no trabalho. } \\
\text { 7. Gostaria de desempenhar funções com maior responsabilidade } \\
\text { 11. Sinto-me com capacidade para gerir um grupo de trabalho. } \\
\text { 15. Sinto necessidade de crescer cada vez mais na minha função. } \\
\text { 19. Se existissem prémios atribuídos aos melhores funcionários, percebia-os como um } \\
\text { fator de motivação profissional. } \\
\text { 23. Um dos meus objetivos é alcançar o cargo mais elevado dentro da organização. } \\
\text { 27. Sinto-me motivado(a) quando o trabalho é elogiado pelo meu superior. }\end{array}$ \\
\hline Envolvimento & $\begin{array}{l}\text { 4. Normalmente considero-me uma pessoa com grande motivação. } \\
\text { 8. Considero o meu trabalho monótono. } \\
\text { 12. Sinto-me envolvido(a) emocionalmente com a organização. } \\
\text { 16. Os meus conhecimentos são determinantes na forma de trabalhar. } \\
\text { 20. Aborreço-me quando não compreendo a finalidade das minhas funções. } \\
\text { 24. Identifico-me com a função que desempenho. } \\
\text { 28. Trabalharia com maior empenho se existissem formas de remuneração alternativa. }\end{array}$ \\
\hline
\end{tabular}

Fonte: Ferreira et al., 2006.

Da maneira que foi realizada no estudo de construção e validação da escada Multi-Moti, as afirmações constantes nos itens/fatores foram associadas a uma escala de resposta do tipo 
Likert com cinco tipos de respostas alternativas, cujos posicionamentos oscilaram entre os polos, 1 - discordo totalmente e 5 - concordo totalmente.

Seguindo a mesma referência, na análise dos dados tomou-se o cuidado ainda de se inverterem os escores dos itens 8, 20 e 28 pois as afirmativas se apresentavam na negativa.

Dessa forma, com os valores variando de cinco pontos no intervalo de 1 (um ponto) a 5 (cinco pontos), o escore 5 foi vinculado ao mais alto nível de motivação e o 1 ao menor.

Participaram do estudo 57 servidores de uma população total de 79. A amostra buscou contemplar o máximo de indivíduos dispostos a contribuir com o trabalho de pesquisa, tendo por fim compreendido servidores efetivos de todos os setores da unidade da instituição em estudo.

O questionário foi elaborado no aplicativo Google Drive através da ferramenta Formulários Google. Sua aplicação ocorreu por meio da disponibilização de um endereço virtual, encaminhado via e-mail institucional para todos os servidores entre os meses de novembro de 2017 a fevereiro de 2018.

Após a aplicação do questionário os dados foram tabulados e agrupados em planilhas eletrônicas. Extraíram-se as representatividades demográficas da amostra e procederam-se os tratamentos estatísticos descritivos e inferenciais. Inicialmente foram obtidos o escore médio e desvio padrão da amostra como um todo, e, depois, segmentados em aspectos demográficos e também em dimensões da sub-escala Multi-Moti. Por fim, separaram-se os dados relativos a cada dimensão da escada de motivação e extraíram-se os escores médios e desvios padrão novamente em subdivisões de aspectos demográficos.

\section{Resultados}

Contando com voluntários de todas as repartições da unidade objeto da pesquisa, o estudo teve a participação de 57 respondentes, os quais representaram a fração de $72,15 \%$ dos servidores efetivos da unidade. Desses, 45(78,95\%) indivíduos do sexo masculino e $12(21,05 \%)$ do sexo feminino. Trinta e nove $(68,42 \%)$ servidores ocupantes de cargos em setor técnico e $18(31,58 \%)$ ocupantes de cargos em setor administrativo. 
No que diz respeito à idade dos respondentes observou-se a predominância de pessoas da faixa etária na casa dos 45 a 65 anos, estando representada por 34(59,65\%) respondentes. Com menos de 45 anos foram 20(35,09\%) e com mais de 65 anos, 3(5,26\%).

Quanto ao grau de escolaridade requerido pelo cargo ocupado pelo respondente observou-se que 31(54,39\%) indivíduos pesquisados ocupavam cargo de nível superior e 26(45,61\%) de nível fundamental ou médio. Já em relação ao tempo de serviço prestado à instituição, assim como no dado anterior, foi verificado equilíbrio na distribuição dos respondentes, 24(42,11\%) servidores com 20 anos ou mais na instituição, 21(36,84\%) com 10 a menos 20 anos, e 12(21,05\%) com menos de 10 anos de serviço prestado ao órgão.

A Tabela 1 revela as médias gerais dos escores relativas às dimensões de motivação da Escala Multi-Moti. Desta feita, atingindo 3,31 pontos, o escore médio geral calculado evidenciou um sinal positivo de percepção da motivação dos respondentes.

Tabela 1. Estatística descritiva das sub-escalas Muti-Moti.

\begin{tabular}{lcc}
\hline Sub-escalas motivacionais (Multi-Moti) & Média & $\begin{array}{c}\text { Desvio- } \\
\text { Padrão }\end{array}$ \\
\hline Realização e Poder & $3,70^{\mathrm{a}}$ & 1,08 \\
Desempenho & $3,42^{\mathrm{b}}$ & 1,08 \\
Envolvimento & $3,38^{\mathrm{b}}$ & 1,21 \\
Organização do trabalho & $2,74^{\mathrm{c}}$ & 1,22 \\
\hline Amostra & $\mathbf{3 , 3 1}$ & $\mathbf{1 , 2 0}$ \\
\hline
\end{tabular}

* As médias seguidas pela mesma letra não diferem entre si, pelo Teste t de Student, a 5\% de probabilidade. Anova: $\mathrm{F}(3,1592)=49,72 ; \mathrm{p}<0,05$.

Fonte: Elaborada pelo autor.

$\mathrm{Na}$ tabela a seguir são exibidos os resultados da análise na qual foram levadas em consideração as dimensões de motivação associadas à Escala Multi-Moti de motivação para o trabalho perante as variáveis demográficas dos respondentes. Nela são apresentadas as médias com desvios individualizados e resultados das suas respectivas análises de variância (ANOVA) seguidos dos significados estatísticos existentes entre médias. 
Tabela 2. Estatística descritiva e inferencial dos dados demográficos x sub-escalas Multi-Moti.

\begin{tabular}{|c|c|c|c|c|}
\hline \multirow{2}{*}{ Variável } & \multicolumn{4}{|c|}{ Sub-escalas Multi-Moti } \\
\hline & Organização & Desempenho & Realização e Poder & Envolvimento \\
\hline & Média / DP & Média / DP & Média / DP & Média / DP \\
\hline \multicolumn{5}{|l|}{ Gênero } \\
\hline Masculino & $2,73 / 1,22$ & $3,42 / 1,07$ & $3,72 / 1,07$ & $3,38 / 1,18$ \\
\hline \multirow[t]{2}{*}{ Feminino } & $2,77 / 1,24$ & $3,40 / 1,15$ & $3,61 / 1,14$ & $3,37 / 1,32$ \\
\hline & $\begin{array}{c}\mathrm{F}(1,397)=0,07 \\
\mathrm{p}>0,05\end{array}$ & $\begin{array}{c}\mathrm{F}(1,397)=0,01 \\
\mathrm{p}>0,05\end{array}$ & $\begin{array}{c}\mathrm{F}(1,397)=0,76 \\
\mathrm{p}>0,05\end{array}$ & $\begin{array}{c}F(1,397)=0,003 \\
p>0,05\end{array}$ \\
\hline \multicolumn{5}{|l|}{ Faixa etária } \\
\hline \multirow{4}{*}{$\begin{array}{l}<45 \text { anos } \\
45 \text { a }<65 \text { anos } \\
>65 \text { anos }\end{array}$} & $2,39 / 1,16$ & $3,17 / 1,07$ & $3,47 / 1,23$ & $3,32 / 1,18$ \\
\hline & $2,94 / 1,22$ & $3,53 / 1,09$ & $3,78 / 0,98$ & $3,39 / 1,21$ \\
\hline & $2,86 / 1,15$ & $3,71 / 0,85$ & $4,29 / 0,85$ & $3,62 / 1,32$ \\
\hline & $\begin{array}{c}\mathrm{F}(2,396)=9,60 \\
\mathrm{p}<0,05\end{array}$ & $\begin{array}{c}\mathrm{F}(2,396)=5,91 \\
\mathrm{p}<0,05\end{array}$ & $\begin{array}{c}\mathrm{F}(2,396)=7,05 \\
\mathrm{p}<0,05\end{array}$ & $\begin{array}{c}F(2,396)=0,57 \\
p>0,05\end{array}$ \\
\hline \multicolumn{5}{|l|}{ Setor ocupado } \\
\hline \multirow{3}{*}{$\begin{array}{l}\text { Administrativo } \\
\text { Técnico }\end{array}$} & $2,75 / 1,18$ & $3,45 / 0,93$ & $3,53 / 1,06$ & $3,36 / 1,14$ \\
\hline & $2,74 / 1,24$ & $3,40 / 1,15$ & $3,78 / 1,09$ & $3,38 / 1,24$ \\
\hline & $\begin{array}{c}\mathrm{F}(1,397)=0,002 \\
\mathrm{p}>0,05\end{array}$ & $\begin{array}{c}\mathrm{F}(1,397)=0,20 \\
\mathrm{p}>0,05\end{array}$ & $\begin{array}{c}\mathrm{F}(1,397)=4,43 \\
\mathrm{p}<0,05\end{array}$ & $\begin{array}{c}\mathrm{F}(1,397)=0,04 \\
\mathrm{p}>0,05\end{array}$ \\
\hline \multicolumn{5}{|l|}{ Esc. do cargo } \\
\hline \multirow{3}{*}{$\begin{array}{l}\text { Fund./Médio } \\
\text { Superior }\end{array}$} & $2,96 / 1,30$ & $3,60 / 1,03$ & $3,83 / 1,07$ & $3,41 / 1,27$ \\
\hline & $2,56 / 1,12$ & $3,26 / 1,10$ & $3,59 / 1,09$ & $3,35 / 1,15$ \\
\hline & $\begin{array}{c}\mathrm{F}(1,397)=10,52 \\
\mathrm{p}<0,05\end{array}$ & $\begin{array}{c}\mathrm{F}(1,397)=10,35 \\
\mathrm{p}<0,05\end{array}$ & $\begin{array}{c}\mathrm{F}(1,397)=4,88 \\
\mathrm{p}<0,05\end{array}$ & $\begin{array}{c}\mathrm{F}(1,397)=0,29 \\
\mathrm{p}>0,05\end{array}$ \\
\hline \multicolumn{5}{|l|}{ Tempo serviço } \\
\hline \multirow{4}{*}{$\begin{array}{l}<10 \text { anos } \\
10 a<20 \text { anos } \\
>20 \text { anos }\end{array}$} & $2,46 / 1,21$ & $3,32 / 1,12$ & $3,70 / 1,13$ & $3,43 / 1,17$ \\
\hline & $2,45 / 1,08$ & $3,21 / 1,07$ & $3,52 / 1,13$ & $3,28 / 1,19$ \\
\hline & $3,14 / 1,24$ & $3,64 / 1,04$ & $3,86 / 1,00$ & $3,43 / 1,24$ \\
\hline & $\begin{array}{c}\mathrm{F}(2,396)=16,33 \\
\mathrm{p}<0,05\end{array}$ & $\begin{array}{c}F(2,396)=6,83 \\
p<0,05\end{array}$ & $\begin{array}{c}\mathrm{F}(2,396)=3,91 \\
\mathrm{p}<0,05\end{array}$ & $\begin{array}{c}\mathrm{F}(2,396)=0,75 \\
\mathrm{p}>0,05\end{array}$ \\
\hline
\end{tabular}

Nota: Média- média dos escores; DP- desvio padrão dos escores; $\mathrm{F}$ = valor $\mathrm{F}$ da ANOVA; $\mathrm{p}=$ probabilidade. Fonte: Elaborada pelo autor.

\section{Discussão}

O estudo, buscando identificar o nível de motivação dos servidores, vem demonstrar evidências da existência de uma percepção motivacional positiva. Tanto que a média geral dos escores obtidos da amostra, numa escala gradual de 5 pontos, foi 3,31 (Tabela 1), valor tendencialmente mais próximo do nível mais alto de motivação do que do contrário. 
No que diz respeito a variabilidade dos valores obtidos verificou-se ter ocorrido um elevado desvio padrão. Algo que não surpreende e nem compromete a mostrar, visto ser, em estudos dessa natureza, admissível e até desejável, uma vez que quanto mais heterogênea a amostra mais representativa da extensão da população ela é (CLARK \& WATSON, 1995, apud LAROS, 2012). Nessas circunstâncias, dada a alta dispersão amostral, resta deduzir que muito provavelmente não se tratou de uma amostra viciada.

Os escores médios apresentados na Tabela 1, a exceção do registrado para a dimensão percepção de motivação do trabalho, atingiram valores positivos, acompanhando o índice geral da amostra que foi acima de 3,00 pontos e respaldando o resultado motivacional geral do grupo estudado.

Distinguiu-se também a ocorrência de variações numéricas significativas entre os valores, destacando-se as dimensões de percepção de motivação de realização e poder, que se sobressaiu positivamente e a de percepção de organização do trabalho que obteve resultado negativo do ponto de vista motivacional.

A percepção de realização e poder, dimensão que se destacou positivamente, segundo a perspectiva de McClelland (1987), está vincula a necessidades de realização, poder e/ou filiação. Segundo ele, pessoas quando possuem necessidade de realização gostam de assumir responsabilidades e/ou riscos, quando possuem necessidade de poder desejam influenciar e controlar o comportamento dos outros assumindo-se competitivas, e, quando possuem necessidade de afiliação preferem situações mais cooperantes que competitivas.

Para uma melhor compreensão dos resultados auferidos foi realizado um contraponto com os itens da escala Multi-Moti, ou seja, com os fatores avaliados. Concernentes à dimensão realização e poder observou-se que três dos sete itens foram cruciais no realce da dimensão, foram eles: 3. Ter perspectivas de carreira é importante para a minha motivação no trabalho (4,16 pontos); 27 . Sinto-me motivado(a) quando o trabalho é elogiado pelo meu superior $(4,11$ pontos); 15. Sinto necessidade de crescer cada vez mais na minha função (4,00 pontos). O que indica na percepção dos respondentes a importância das necessidades de realização de carreira e elevação da autoestima.

Fetzner et al. (2010) afirma que um obrigado ou um simples elogio possam ser realmente importantes fatores de motivação para um desempenho especial, assim como para outros seja necessário ser concreto, como, por exemplo, receber uma promoção, um brinde ou troféu. Por outro lado, para Melo (2013), sugere que quando a empresa não oferece meios que 
proporcionem o crescimento profissional ela tem grande chance de perder seus funcionários qualificados.

Diante dessas afirmações pode-se inferir pelos resultados obtidos que os servidores da unidade estudada respondam relativamente bem a determinados estímulos de realização e poder, sendo dentre as dimensões teóricas aqui propostas aquela que apontou os melhores indicadores motivacionais do grupo. Dentre as principais maneiras de estimulá-los os fatores relacionados ao enaltecimento e valorização atrelados a perspectivas de ascensão profissional demonstraram ser significativamente relevantes.

No que tange a dimensão organização do trabalho o seu resultado ficou aquém do esperado transparecendo uma percepção motivacional negativa. Daí verificou-se dentre os itens que constituem os fatores motivacionais da escala submetida, onde observou-se que aqueles que apresentaram menores índices foram: 9. Sinto-me satisfeito com a minha remuneração (2,11 pontos) e 17. Todos os funcionários da organização participam nos processos de tomada de decisão (2,14 pontos), puxando literalmente a média do conjunto para baixo e consequentemente exteriorizando a falta de motivação associada a percepção de organização do trabalho.

Relativo a satisfação com a remuneração Silva et al. (2012), alega que se bem gerida pode se tornar um fator de atratividade da organização, promovendo o sentimento de valorização e resultando em motivação e produtividade. Afirma também que as organizações públicas continuam desenvolvendo políticas estratégicas de gestão sem a devida atenção e alinhamento com a política de remuneração, e, que em decorrência das transformações no mundo do trabalho, essa situação tem mudando gradativamente já sendo sentida no serviço público que mantem ainda formas de pagamento fixas principalmente ancoradas no fardo burocrático que lhes é de natureza.

Para Lacombe (2005), a percepção de injustiça na remuneração afeta não só o nível material, mas também o bem-estar psicológico das pessoas, se tornando um dos fatos que mais desmotiva o trabalhador.

Quanto à participação na tomada de decisões, Robbins (2010, p. 231) menciona que o aumento do poder de decisão e a maior participação dos empregados nas decisões afetam positivamente a produtividade, vez que incentivam mais comunicação e um ambiente social positivo. Desta feita, o contrário tende a ser desmotivante principalmente pelo fato do trabalhador ter restringida a sua opinião perante as situações que envolvem a sua ação laboral. 
Cabe, portanto, concluir que os resultados insatisfatórios de percepção na esfera organizacional do trabalho tenham um suporte inegável na percepção de injustiça salarial e na falta de participação no planejamento de atividades e tomada de decisão, contemplando entre outras coisas a deficiência da comunicação institucional, visto que fatores como realização e cooperação apresentaram valores semelhantes aos valores médios da amostra geral.

Assim, tem-se que, na ótica das teorias motivacionais aqui propostas pela escala MultiMoti, à exceção dos resultados obtidos quanto a percepção de organização do trabalho, percebeu-se que os servidores da unidade avaliada se encontram de forma geral motivados. Nesse cenário, a expressão da percepção de realização e poder obteve destaque ao ter atingido o índice de motivação mais elevado. Fato esse ocorrido também quando da confecção e validação da escala Multi-Moti por Ferreira et al. (2006).

Na sequência a Tabela 2 apresentou as diferenciações das variáveis demográficas frente às dimensões de motivação da escala. Por meio dela pôde-se desvendar particularidades expressadas por grupos específicos da amostra.

Então, analisando-se essas variáveis individualmente verificou-se que as suas médias seguiram a tendência das médias gerais obtidas nas dimensões motivacionais, ou seja, as médias das variáveis demográficas foram sempre inferiores, manifestando baixa motivação no âmbito da percepção da organização do trabalho e mais elevadas quando relacionadas à percepção de realização e poder, exprimindo percepção positiva de motivação.

Acompanhando o raciocínio no tocante a variável gênero não se distinguiu diferença estatística significativa na percepção motivacional de homens e mulheres em qualquer das dimensões motivacionais avaliadas, corroborando com o estudo de Ferreira et al. (2006). Porém, como já discutido anteriormente, seguindo a amostra geral, a ocorrência das maiores médias esteve atrelada à percepção motivacional de realização e poder.

Relativo à variável faixa etária, aqueles identificados com idade mais avançada se mostraram significativamente mais motivados do que os mais jovens, à exceção exclusiva da percepção para o envolvimento organizacional. Contudo a literatura expressa que independente da idade todos os colaboradores podem ser motivados (McClelland, 1987). O que resta concluir que aqueles com idade mais elevadas talvez se sintam mais motivados em função da maneira que estão sendo estimulados.

Entre servidores ocupantes de cargos de setores técnico e administrativo do órgão a ocorrência de diferença entre médias foi significativa apenas para a sub-escala que mede a 
motivação face a realização e poder, obtendo neste caso também os índices mais altos de motivação no que diz respeito a variável em relação às quatro dimensões motivacionais. Em contraponto Ferreira et al. (2006) identificou diferença somente para a sub-escala organização do trabalho.

Já em relação às variáveis grau de escolaridade requerido pelo cargo ocupado e tempo de serviço prestado à instituição, apenas no que diz respeito à dimensão envolvimento organizacional não foram obtidas diferenças estatísticas significativas entre as categorias das variáveis. Segundo Robbins (2010), as evidências mais recentes indicam uma relação positiva entre o tempo de serviço e o desempenho no trabalho. Quanto ao grau de escolaridade, ele refere que aqueles que possuem nível educacional mais elevado, tendem a utilizar mais de referências do outro-externo, outra pessoa ou grupo de fora da empresa, acabando muitas das vezes por se desmotivarem ao perceberem inequidade.

\section{Conclusão}

O presente trabalho apontou que de forma geral o nível de motivação percebido pelos servidores da unidade organizacional estudada é positivo apresentando como o resultado a média de 3,31 pontos em uma escala de 1 a 5 .

No tocante a diferenciação entre dimensões de motivação associadas a escala MultiMoti, observou-se que os respondentes se demonstraram mais motivados frente a sub-escala de motivação de realização e poder atingindo diferença estatística significativa em relação às demais dimensões.

O elevado nível de motivação percebido na dimensão de realização foi associado principalmente a fatores ligados ao enaltecimento e valorização do servidor atrelados a perspectivas de ascensão profissional, o que faz concluir que esses colaboradores apresentam grande probabilidade de responderem a estímulos dessa natureza.

Relativo às variáveis demográficas em contraponto às dimensões motivacionais verificou-se que, à exceção da sub-escala que mede a motivação face ao envolvimento para o trabalho, em todas as variáveis, salvo gênero, ocorreram diferenciações estatisticamente significativas em uma ou mais dimensões sub-escalares. 
Nessa perspectiva, contatou-se estarem mais motivados aqueles que se apresentaram com idade mais avançada, assim como os ocupantes de cargos de nível escolar fundamental ou médio e os que estão a mais tempo prestando serviço à instituição.

No entanto, no que compete ao setor ocupado pelo servidor só houve variação significativa de percepção face a motivação para a realização e poder, tendo aqueles lotados em divisões técnicas percepção motivacional superior à daqueles assentados em setores administrativos.

Por fim vale dizer que essa investigação teve a iniciativa de apresentar o nível de motivação dos servidores por meio das suas percepções frente a uma escala motivacional conhecida sem a preocupação de revalidá-la, porém estudos mais elaborados sobre a temática, poderão ser realizados, inclusive abrangendo uma população maior, tanto em nível de instituição como um todo ou de mais de uma organização. Sugere-se, para tanto, a amostragem pautada no subsídio aplicação de análise estatística multifatorial de dados.

\section{Referências}

BRUNELli, M. G. M. Motivação no Serviço Público. Porto Alegre: Faculdade IBGEN, 2008. Disponível em: <lproweb.procempa.com.br/pmpa/prefpoa/sma/ usu_doc/maria_da_graca_mello_brunelli._tcc.pdf >. Acesso em: 19 set. 2017.

CHIAVENATO, I. Gerenciando pessoas: o passo decisivo para a administração participativa. 3. ed. São Paulo: Makron Books, 1994.

FERREIRA, A.; DIOGO, C.; FERREIRA, M.; VALENTE, A. C. Construção e validação de uma Escala Multi-Factorial de Motivação no Trabalho (Multi-Moti). Comportamento Organizacional e Gestão, v. 12, n. 2, p.187-198, 2006.

FETZNER, M. A.; OLTRAMARI, A. P.; OLEA, P. M. Gestão do desempenho na administração pública: o caso da TI governo. Rev. adm. contemp. [online]. 2010, vol.14, n.5, pp.968-982. ISSN 1982-7849. Disponível em: <http://dx.doi.org/10.1590/S141565552010000500014>. Acesso em: 04 jun. 2018.

GOMES, A. A. P.; QUELHAS, O. L. G. Motivação dos Recursos Humanos no Serviço Público: Um Estudo de Caso sob Dois Ângulos Teóricos. Revista Eletrônica de

Administração, [S.1.], v. 9, n. 5, set. 2013. ISSN 1413-2311. Disponível em: <http://www.seer.ufrgs.br/index.php/read/article/view/42647/27032>. Acesso em: 19 set. 2017. 
LACOMBE, F. J. M. Recursos Humanos: princípios e tendências. São Paulo: Saraiva, 2005.

LAROS, J. A. O uso da análise fatorial: algumas diretrizes para pesquisadores. In\:

PASQUALI, L. (Org.), Análise fatorial para pesquisadores (pp. 141-160). Brasília: LabPAM Saber e Tecnologia, 2005.

LOPES, G. A. C. Motivação no Trabalho. Rio de Janeiro: Universidade Cândido Mendes, 2003. Disponível em:

<http://www.avm.edu.br/monopdf/23/GABRIELA\%20ALVARENGA\%20COLMENERO\% 20LOPES.pdf >. Acesso em: 10 mai. 2018.

McClelland, D. C. Human Motivation. Cambridge: Cambridge University Press, 1987.

MELO, M. A. R.; PINHO, V. S.; CARNEIRO, S. N. V.; BERNAL, C. C. Motivação: visão de discentes de uma instituição de ensino superior do sertão central. Revista Expressãa

Católica, [S.1.], v. 2, n. 1, jun. 2013. ISSN 2357-8483. Disponível em:

$<$ http://publicacoesacademicas.fcrs.edu.br/index.php/rec/article/view/1317/1080>. Acesso em: 31 mai. 2018.

ROBBINS, S. P.; JUDGE, T. A.; SOBRAL, F. Comportamento Organizacional: teoria e prática no contexto brasileiro. 14. ed. São Paulo: Pearson Prentice Hall, 2010.

SILVA, L. C. J; DE ARAÚJO, P. C. D; REYES JUNIOR, E. A percepção dos gestores quanto às estratégias de remuneração e a motivação no trabalho: um caso no judiciário da Amazônia brasileira. Revista de Administração de Roraima - RARR, [S.1.], v. 2, n. 2, p. 78-94, dec. 2012. ISSN 2237-8057. Disponível em: <https://revista.ufrr.br/adminrr/article/view/1140>. Acesso em: 04 jun. 2018.

YIN, R. K. Estudo de Caso: planejamento e métodos. 4. ed. Porto Alegre: Bookman, 2010.

\section{Como citar este artigo (Formato ABNT):}

SILVA, Adalberto Campinho da; SILVA, Bruno Cezar; SILVA, Maria Gabriela J. Percepção Motivacional dos servidores de uma Instituição Pública Federal. Id on Line Rev.Mult. Psic., 2018, vol.12, n.41, p.206-218. ISSN: 1981-1179.

Recebido: 07/06/2018

Aceito 14/06/2018 